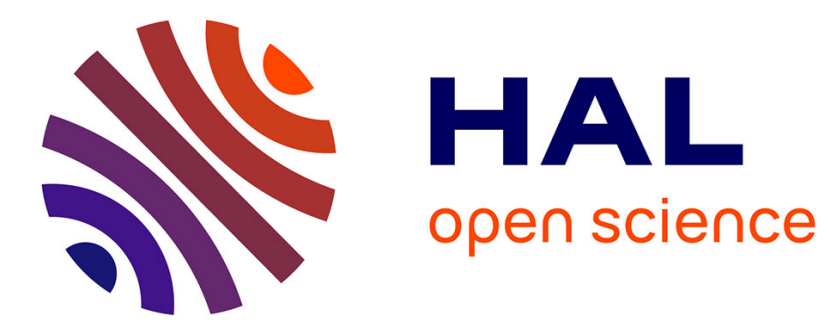

\title{
Para un reexamen de la noción de ambición en la primera parte de La hija del aire de Calderón (1653)
}

Françoise Gilbert

\section{To cite this version:}

Françoise Gilbert. Para un reexamen de la noción de ambición en la primera parte de La hija del aire de Calderón (1653). Simposio internacional: Calderón en un nuevo milenio, May 2011, Chicago, Estados Unidos. pp.305-331. halshs-00943921

\section{HAL Id: halshs-00943921 https://shs.hal.science/halshs-00943921}

Submitted on 11 Feb 2014

HAL is a multi-disciplinary open access archive for the deposit and dissemination of scientific research documents, whether they are published or not. The documents may come from teaching and research institutions in France or abroad, or from public or private research centers.
L'archive ouverte pluridisciplinaire HAL, est destinée au dépôt et à la diffusion de documents scientifiques de niveau recherche, publiés ou non, émanant des établissements d'enseignement et de recherche français ou étrangers, des laboratoires publics ou privés. 


\title{
Para un reexamen de la noción de ambición en la primera parte deLa hija del aire de Calderón (1653) Françoise GILBERT
}

En la magnífica introducción a su edición de La hija del aire, el profesor Ruiz Ramón presenta así a la muy barroca protagonista de la comedia en dos partes:

\begin{abstract}
Semíramis, objeto del deseo de Menón y de Nino, [...] situada en el centro de ese nudo inextricable formado por la cadena de acasos que propicia los encuentros entre los personajes [...] y por la «ambición» y la «hermosura» que definen su doble naturaleza como personaje, asociada, desde antes de su nacimiento, con la diosa cazadora, la fría y agresiva Diana, y la diosa del Amor, la ardiente y seductora Venus, avasallará todos los obstáculos que se opongan a su ascenso al poder, que es ascenso a su propio destino, cumplido inexorablemente al final de su trayectoria dramática. ${ }^{1}$
\end{abstract}

De modo casi unánime, la crítica reconoció en el personaje de Semíramisuna figura de la ambición - en el sentido de «deseo ardiente de conseguir poder, riquezas, dignidades o fama $^{2} »$.La primera parte de la obra, que dramatiza el ascenso de Semíramis, sería una ilustración de su ambición o afán de poder, mientras que la segunda parte ejemplificaríasu vana lucha para conservar este poder, y su caída ${ }^{3}$. Stephen Lipmann ${ }^{4}$ pone en tela de juicio esta lectura de la ambición de la protagonista en un artículo dondeanalizaeste concepto más bien como un deseo de homenaje- "recognition" en palabras del crítico-relacionado con lanoción de honor en latín, tal como Santo Tomás lo concibe. Prolonga esta aserción con una interpretación del personaje de Semíramis como una mujer con alma de hombre, cuya ambición es galvanizada por sus cualidades, tradicionalmente masculinas, de brío y valor, y eso en la primera y en la segunda parte de la obra. De ahí que rechace una interpretación de la comedia como una lección moral sobre el demonio de la ambición, para leerla más bien como una tragedia de inspiración griega,dondela protagonista se ve instrumentalizada en el conflicto que opone a dos deidades 5 .

\footnotetext{
${ }^{1}$ Ruiz Ramón, 1987, p. 30.

${ }^{2}$ DRAE, s. v. 'ambición'.

${ }^{3}$ Véase Edwards, 1970, pp. xxii; p. xxxviii: «While the sources portrayed her as a beautiful, intelligent, ambitious and lustful, Calderón selected beauty and ambition as her predominant characteristics»; xlii: «The theme of ambition, a passion just as powerful as lust, is personified in the Primera Parte in the character of Semíramis herself»; xliii, xlvi y lii; McKendrick, 1974, p. 204; Hesse, 1983, p. 152, p. 153 y p.157; Ruiz Ramón, 1987, p. 23; Regalado, 1995, I, p. 854: «una ambición infinita»; pp. 864-866; Cruisckshank, 2002, p. 358; Froldi, 2003, pp. 147-148; Weimer, 2008 p. 403; .

${ }^{4}$ Véase Lipmann, 1982, p. 42: «First, critics have taken her ambition as a desire for power, when it is primarily 'an unbalanced desire for recognition (Lat., honor)' as St Thomas Aquinas defines the term».

${ }^{5}$ Véase Lipmann, 1982, p. 44: «Whether or not Semíramis is fated to be ambitious or proud, her destiny results directly from the antagonism between two proud rival goddesses, and she is fated to be the instrument of Diana's revenge on Venus».
} 
Quisiera explorar algunasde las pistas abiertas por Lipman y estudiar primero cómo, desdelos versos aperturales del texto y a lo largo deesta primera secuencia en romance ${ }^{6}$, el motor de las acciones de la protagonista no es el rasgo moral de la ambición, sinoefectivamente el ansia dehonor, o sea de «consideración, estima, homenaje ${ }^{7}$ »Pero también quisiera mostrar cómo la trayectoria dramáticade Semíramis a lo largo de la primera parte no se elabora a partir de especificidades fundamentalmente psciológicas ${ }^{8}$, sino ante todo a partir de mecanismos de caracterización propios de la comedia áurea, como el del valor intrínseco a la sangre, primordialen los héroes calderonianos ${ }^{9}$. De ahí que llegue a matizar su caracterización por la ambiciónen su acepción exclusivamente negativa de"apetito excesivo de honor", para analizar cómo, hasta el final de la segunda jornada, esta ambición es prioritariamente la expresión de su configuración como protagonista heroica.

Empezaréanalizando los primeros versos de la primera jornada, donde ya se plasman las cualidades heroicas de la protagonista cuando, al percatarse de los ruidos provocados por la vuelta triunfante del rey Nino a su corte, Semíramis desea escapar de la gruta en que la confinan la ira de Diana y el oráculo de Venus.

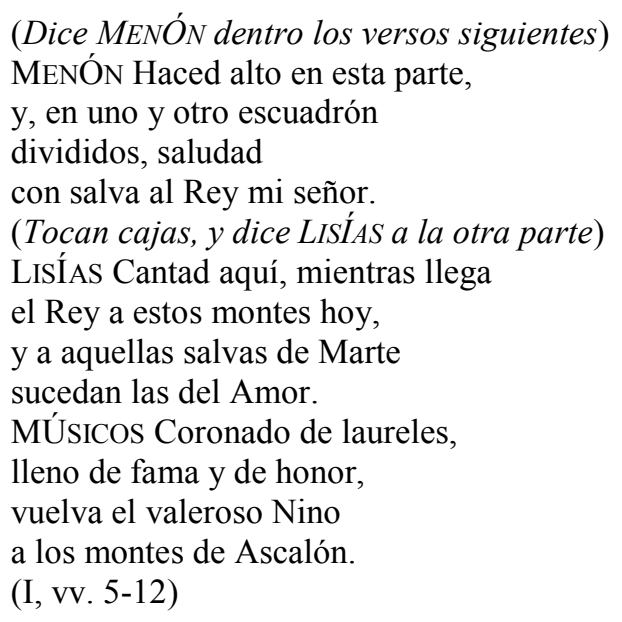

La música contrastada que acompaña estosversos iniciales, calificada por Tiresias como «tan desconforme unión / de músicas» (vv. 22-23), ha sido interpretada, incluso por

\footnotetext{
${ }^{6}$ Véase Güell, 2004, para la estructura dramática de la obra a partir de los datos métricos.

${ }^{7}$ Véase Gaffiot, 2000, s.v. 'honor, honos, oris'.

${ }^{8}$ Véansecomo ejemplos de anánlisis psicológicos, Edwards, 1970, y Fisher, 1982.

${ }^{9}$ Véase Vitse 1999, p. 39: «Chaque personnage de La vida, chaque être dramatique caldéronien pourrait alors être situé selon cette échelle de la valeur». Aunque parezca exponer la misma idea en otros términos, Regalado, 1995, I, p. 858no la relaciona con la supuesta "ambición" de la protagonista: «El impulso que mueve a Semíramis es ese apetito de actualidad (conatus ad Existentiam) que transciende los motivos psicológicos que tiende a buscar el lector moderno. [...] Ante las amenazas de Tiresias, que la ordena volver a la cueva, Semíramis, abandonada a la desesperación que la consume, opta por la arriesgada libertad (experiencia) frente a la seguridad de la prisión».
} 
Lipmann $^{10}$, como representativa de la dualidad fundamental del personaje de Semíramis. Según la lectura del profesor Ruiz Ramón, esta escena apertural

invita al espectador a ver la acción simultáneamente desde dos puntos de vista o focos dramáticos, representados por la división del área escénica en dos espacios dramáticos: el abierto y libre, donde suenan las contrarias músicas de Venus y Marte, y en el que aparecerá el victorioso rey Nino, nimbado por la gloria y la alegría del triunfo, y el cerrado de la gruta, en donde Semíramis se encuentra prisionera [...]. La división de espacios es duplicada a su vez en el plano acústico por la división de las músicas: la marcial y guerrera de tambores y clarines, bajo el signo de Marte, y la dulce y blanda de voces e instrumentos suaves bajo el signo de Venus ${ }^{11}$.

Si bien es obvia la relación entre la música guerrera de los soldados y el dios Marte ${ }^{12}$, resulta más difícil ver una referencia a Venus en estos primeros versos pronunciados por Lisías en respuesta a las marciales salvas de las tropas encabezadas por el general Menón. A pesar de la mayúscula puesta a la palabra «amor» del verso 8 por la mayoría de los editores ${ }^{13}$, me parece poco probable que esta palabra designea la diosa Venus en estos versos aperturales, en los que todavía no se vislumbra ninguna intriga amorosa. Tampoco se justificauna referencia a Venus cuando, saliendo Tiresias a escena, vuelve a insistir en el contraste entre «[Allí] las trompetas y cajas / de Marte bélico horror, / y allí voces e instrumentos, / dulces lisonjas de amor» (vv. 17-20) —aquí sin mayúscula en las ediciones. Semíramis define este acento como «éste que dulce sonó / con dulces halagos» (vv. 56-57), y Tiresias calificará luego esta música procedente del pueblo de «dulce elevación» (v. 106), pero tampoco me parece sostenible que se trate aquí del sentimiento amoroso, ni tampoco de la fuerza erótica que se suele atribuir a la música $^{14}$.

\footnotetext{
${ }^{10}$ Véase Lipmann, 1982, p. 44-45: «Before revealing Semíramis destiny, Calderón uses music at the start of the Primera parte to establish dramatically and symbolically the dual nature of his heroine. [...] The effects of the music on Semíramis foreshadow her reactions to peaple and situations later in the Primera parte, and symbolically represent the fundamental division in her nature».

${ }_{11}^{11}$ Ruiz Ramón, 1987, p. 20.

${ }^{12}$ Comparto por completo el análisis de Hernández Araico, 1985, pp. 32: «Su temperamento bélico se nota ya desde el principio de la obra por el efecto que produce en ella el son marcial del cortejo del rey Nino [...]. Es evidente entonces su atracción nata por la guerra».

${ }^{13}$ Véase Edwards, 1970, p. 3; Ruiz Ramón, 1987, p. 69. Regalado, 1995, I, p. 853, dice: «Al concluir Semíramis su parlamento, suenan simultaneamente [las dos músicas], caótica amalgama de dos masas sonoras, una instrumental (la de Marte), la otra vocal (la de Venus), aquella disonante y esta melódica, que inundan el teatro llevando a su extremo ese unir contrastando elementos que caracteriza la nueva música. Al hacer que las dos músicas sean ejecutadas conjuntamente el dramaturgo se propuso concertar desconcertando («tan disconforme unión de músicas», dice admirado Tiresias), produciendo un caos de impresiones acordes con las pasiones que desgarran a la protagonista».

${ }^{14}$ Véase Lipmann, 1982, p. 44-45: «[...] Although she displays self-awareness, differentiating her responses to the two kinds of music, she cannot identify valor as a masculine characteristic. The languor induced by the singing looks ahead to the passivity and submissiveness she will show toward Menón as she adopts a sterotypically feminine stance; it is appropriate that the canción dull her senses, commonly associated with the flesh rather than the spirit». Véase también Regalado, 1995, I, p. 853: « Semíramis escucha por primera vez las músicas que la hacen cobrar conciencia de sus pasiones, el doble efecto («blandura y fiereza») del «bronce» y la «canción», la guerra y la paz, la ambición y el amor. Las músicas (armónicas voces y el bronco sonido de
} 
Lo que traduce esta nueva alusión al amor no es sino el entusiasta halago ${ }^{15}$ de la población de Ascalón quien, guiada por Lisías, aclama al rey victorioso para celebrar su vuelta hacia Nínive ${ }^{16}$. Cuando dejan el paño para salir a escena los MÚsICOS vestidos de villanos, LiSÍAS, CHATO Y SIRENE (v. 200+), se confirma que esta música corresponde más bien a los homenajes rendidos al rey victorioso, efusióndesignada por el propio Nino como «el noble celo / con que Ascalón recibe mi persona» (vv. 216-217). Finalmente, Lisías explicita el sentimiento del pueblo al declarar «que, aunque es verdad que yo le he gobernado, / este amor no se debe a mi cuidado, / sino a su gran lealtad» (vv. 219-221).

Parece obvio, por consiguiente, que la interpretación de la dualidad musical señalada por Ruiz Ramón como «las contrarias músicas de Venus y Marte», no es pertinentepara estos versos,en lo que a Venus y su fuerza erótica se refiere.Propondré otro funcionamiento de este trasfondo sonoro, examinando ahora cómo, por su parte,Semíramis recién liberada evoca las emociones convergentes que estas dos músicas generan en ella:

\author{
SEMÍRAMIS Dos acentos \\ que a un tiempo el aire veloz \\ pronuncia, dando a mi oído \\ los dos equivocación, \\ por no haberlos escuchado \\ jamás $[\ldots]$ \\ confusamente los dos \\ me elevan y me arrebatan: \\ éste que dulce sonó, \\ con dulces halagos, hijos \\ de su misma suspensión; \\ éste que, horrible, con fieros \\ impulsos, tras quien me voy, \\ sin saber dónde, y que iguales \\ me arrancan del corazón \\ blandura y fiereza, agrado, \\ ira, lisonja y horror; \\ cuando un estruendo a esta parte, \\ cuando a ésta una admiración; \\ ésta adormece el sentido, \\ ésta despierta el valor,
}

trompetas y cajas destempladas) no identifican ningún objeto representable, sino ímpetus indefinidos que hospedan la desmesurada ambición de Semíramis y la dimensión «femenina» de su personalidad que sobrepasa quijotescamente los límites del objeto representado, saltando sobre la experiencia y anticipándola apriorísticamente».Véase también Quintero, 2001, p. 161.

${ }^{15}$ Se trata del amor de los vasallos o súbditos por su príncipe, como el de los villanos de Fuenteovejunay su carmen triunfale, por ejemplo. Véase Vitse, 1988, p. 435 sq.

${ }^{16}$ Es lo que Tiresias explica a Semíramis algunos versos más lejos: «Sabrás, pues, que Nino, Rey / de Siria, ya vencedor / de las bárbaras naciones / del Oriente, vuelve hoy / a Nínive, corte suya; / por aquí pasa, y al son / de sus cajas y trompetas, / lenguas del sangriento dios, / los rústicos moradores / de los montes de Ascalón / le aclaman» (I, vv. 93-103). Así lo identifica Regalado, 1995, I, p. 859, pero sigue relacionándolo con Venus: «Esta escena se desarrolla en la plaza de Ascalón al recibir los pacíficos habitantes de la provincia al victorioso rey Nino, encuentro en el que se hacen «visibles» las dos músicas, la del amor y la paz y la de la guerra y el poder». 
repitiendo los ecos

del bronce y de la canción...

(Tocan junto, música y cajas)

MÚsICOS A tanta admiración

suspenso queda en su carrera el Sol.

(I, I, vv. 43-72)

Cuando Ruiz Ramón concluye que «A la división exterior entre la música de Venus y la de Marte [...] corresponde la división interior de la protagonista, prefigurada por la división entre Diana y Venus» ${ }^{17}$, no parece reparar en que estas supuestamenteencontradas músicas producen un efecto concordante, y no contradictorio, en Semíramis ${ }^{18}$. De hecho, ella misma subraya que «los dos / me elevan y me arrebatan ${ }^{19} »(\mathrm{vv} .54-55)$, «iguales / me arrancan del corazón / blandura y fiereza, agrado, etc.» (vv. 60-63). Y aunque Semíramis finalmente confiesa sudoble reacción antitética(«ésta adormece el sentido, / ésta despierta el valor» vv. 67-68), los dos sonidos acaban fusionando en una misma melodía y una misma letra, retomada en coro por el conjunto de los músicos y los soldados, a modo de ilustración sonora de su convergencia en la protagonista.

Por su parte, desde su salida a escena «confuso y medroso» (v. 28), Tiresias ${ }^{20}$ certeramente ha presentido al oír la reunión de «el militar aparato / y la dulce elevación» (vv. 106-107), el eco que suscitan estas músicas en la cautiva: sabe - precisamente porque le toca custodiara Semíramis desde su infancia- que «esas novedades dos»(v. 80), generando«en [s]u altiva condición / nuevos deseos» (vv. 82-83), no pueden sino reavivar lo que impulsarásu rebelión contra su destino adverso: hablo del valor ${ }^{21}$ que habita a Semíramis. Este valor es loque ya la animaba, en sus primeras réplicas,aconsiderar la eventualidad de darse muerte si no la liberaban, y sigue siendo lo que se explicita cuando, vencidos ya los recelos delanciano, sale Semíramisde su gruta y confirma que el estruendo del triunfo «despierta su valor» (v. 68). Pocos versos después, una vez enterada delaprocedencia de los

\footnotetext{
${ }^{17}$ Ruiz Ramón, 1987, p. 21.

${ }^{18}$ Bien ha visto Chiappini la convergencia de lo que parece ser como oposición, pero la relaciona con la oposición amor/guerra. Véase Chiappini, 1996, pp. 130-131: «Semíramis se propone como oxímoron, como convivencia simultánea totalmente actuada, contradicción sí, pero racionalmente aceptada, querida y asegurada por la voluntad clara y la serena determinación de oponerse al hado por medio del "juicio", de la "razón". En realidad, Semíramis, por su ambición de poder y de dominio, también contra los quereres del hado, no se da cuenta de que, exactamente, sus "señas" y su naturaleza y condición contienen esta dramática contradicción $[\ldots] \gg$.

${ }^{19}$ Véase Diccionario de Autoridades, s. v. "arrebatar": «3. Vale también elevar, embelesar, causar admiración y asombro, dejando a uno como pasmado y absorto. 4. Metafóricamente vale transportar, enajenar, privar y casi cegar a uno, sacándole fuera de sí y de la razón, y así del que se deja llevar ciegamente de la vehemencia de las pasiones, como ira, cólera, venganza, amor y otros afectos del ánimo, se dice que se arrebató y cegó».

${ }^{20}$ Véase, sobre este personaje, el interesantísimo artículo de Weimer, 2008.

${ }^{21}$ Véase Vitse, 1978, pp. 32-34; 1983, pp. 532-537; 1999, p. 38.
} 
confusos ruidos que oye, Semíramis avisa a su guarda: «hoy / la margen de tus preceptos / ha de romper mi ambición» (vv. 113-115).

Pronunciada por primera vez en la obra por la propia protagonista, lapalabra de «ambición», en el contexto que acabamos de definir, no puede tener el sentido, que ya indiqué, de «deseo ardiente de conseguir poder, riquezas, dignidades o fama»: resultaría poco coherente que, al principio de su trayectoria dramática, y después de unos quince años ${ }^{22}$ pasados fuera de cualquier sociedad organizada, se autopresentara esta mujer vestida de pieles acudiendo a criterios sociales o morales. En cambio, si le damos a la palabra «ambición» el sentido tomista, identificado por Lipmann, como «inordinatumappetitum honoris» ${ }^{23}$, aparece a las claras la conexión estrecha que reúne en la protagonista «valor» y «ambición», como previamente se fundían en un solo coro de las dos músicas de triunfo militar y de homenaje del pueblo: no funcionan sino como dos manifestaciones de la índole dramática esencialmente heroica de la protagonista. El reto que se le plantearáluego a Semíramis, configurando el nudo del conflicto dramático, será mantener el equilibrio o justa medida para que no se haga «inordinatum», o sea excesivo, este appetitum honoris, pasando de appetitus a passio que provoque su caída.

De momento, sigamos con la caracterización inicial de la protagonista. Bien ha señalado Lipmann «las metonimias esencialmente masculinas de "ambición”, "presunción”, “valor" [...] y "brío" ${ }^{\text {" } » ~ p o r ~ l a s ~ q u e ~ S e m i ́ r a m i s ~ s e ~ a u t o d e s i g n a ~ e n ~ s u s ~ p a r l a m e n t o s, ~ p e r o ~ l a s ~}$ relaciona con la dualidad psicológica intrínsecaa su personalidad, generadora de una imaginación indomablefuente,parala heroína,deuna imagen errónea de sí misma ${ }^{25}$. En otra perspectiva, teatral esta vez, Susana Hernández Araico reconoce en Semíramis un compendio de estereotipos femeninos dela tradición dramática áurea, entre los que el de la mujer varonil, la serrana, la mujer encerrada, la mujer esquiva, o la falsamente ingenua ${ }^{26}$. Pero deduce que este conjunto, origen de la personalidad conflictiva deSemíramis, «ha acuciado su ambición al

\footnotetext{
${ }^{22}$ Véase Cruickshank, 2002, p. 361, nota 4: «In Part 1, Semíramis is only fifteen, if we are to take the "tres lustros" (v. 631) of Lisías as an indication of how long ago she was born; in Part 2, she is aged "cuarenta años más o menos" (v. 652) if Chato's remark is to be taken seriously».

${ }^{23}$ Véase Summa Theologica [44359] II ${ }^{\mathrm{a}}$-IIae, q. 131, a. 1: «Ambitio autem importat inordinatum appetitum honoris».

${ }^{24}$ Véase Lipmann, 1982, p. 45: «With Tiresias, she speaks aggressively, referring to herself in metonymies that are essentially masculine: 'ambición', 'presunción' and 'valor'».

${ }^{25}$ Véase Lipmann, 1982, p. 45: «Semíramis fames her heroic choice because she is desesperate to be free, and she forgets that a third course, that of reason, is theoretically open to her. [...] Her valor predominates, but this display of bravado is also a somkescreen: Semíramis refuses to admit tha as a woman she is physically at a disadvantage against Tiresias guards».

${ }^{26}$ Véase Hernández Araico, 1985.
} 
poder y a la gloria» ${ }^{27}$, y concluye que «Representando varios tipos tradicionales de mujer varonil y femenil, la protagonista intenta reconciliar los aspectos contradictorios de su personalidad por medio de fingimientos ${ }^{28} \gg$.A su vez, Regalado,en una aproximación más bien filosófica, ve en Semíramis una figura del mal correspondiendo «al dinamismo de la voluntad,al espíritu creativo» que cuaja en el impulso hacia la existencia ${ }^{29}$.

Por mi parte, quisieraprofundizar en el análisis del origen en la protagonista de estas nociones de ambición, valor y brío, para demostrar que no son sino la marca de su caracterización heroica, que se revelará muy coherente, desde un punto de vista dramático, a lo largo de lasdos primerasjornadasde la primera parte. Así, despuésde recordar ante Tiresias el oráculo nefasto de Venus según el cual Semíramis provocará «tragedias, muertes, insultos / ira, llanto y confusión» (vv. 137-138), y «que a un Rey / glorioso la haría [su] amor / tirano, y que al fin vendría / a darle la muerte [ella]» (vv. 139-142), la cautiva enfurecidadesafía por segunda vez el hado,volviendo a convocar su «ambición»:

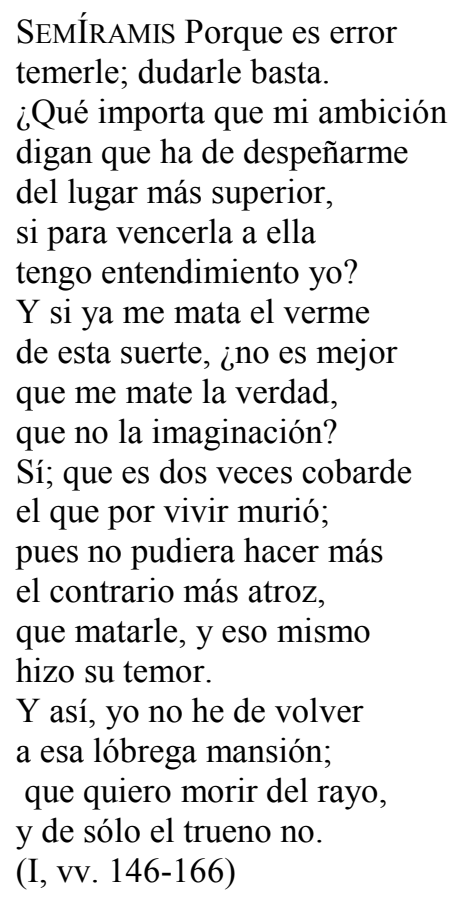

\footnotetext{
${ }^{27}$ Véase Hernández Araico, 1985, p. 33.

${ }^{28}$ Véase Hernández Araico, 1985, p. 39.

${ }^{29}$ Véase Regalado, 1995, I, p. 887. Véanse también pp. 882-883: «El objeto del deseo de Semíramis es el deseo mismo, la voluntad de la voluntad, el querer querer ser o querer querer no ser, antes que no querer ser o no querer no ser, conatus que explaya una voluntad de poder que se levanta hasta lo sublime. [...] Si acudimos a la metafísica de Leibniz descubriremos que esa voluntad de la voluntad cuya medida está en sí misma recibe el nombre de conatus ad Existentiam, o impulso hacia la existencia, principio que fundamenta el axioma que dice que hay un orden en la naturaleza, que algo existe más bien que no»; pp. 906-907: «En La hija del aire la protagonista se enfrenta con su destino, poniendo a prueba la verdad del vaticinio que la condena por anticipado [...]. El insaciable apetito de realidad que mueve la voluntad del personaje se hace sentir como un impulso o conato de existir patente en los mismos efectos escénicos, en el esfuerzo por salir de la cueva al gran teatro del mundo, a ex-sistir en el sentido que, por ejemplo, Cicerón usa el término “ex-sistere speculo”».
} 
La retórica bélica del «valor» — «ambición» (v. 148), «vencer» (v. 151), «matar» (vv. 153, 155 y 161), «contratrio» (v. 160), «morir» (v. 165) — opuesta a la del «temor»—《temerle» (v. 147), «cobarde» (v. 157), «temor» (v. 162)—, si bien confirma la dimensión varonilde la protagonista como arquetipo teatral, es sobre todo indicio de la concepción heroicoaristocrática tantas veces desarrollada en la comedia nueva, y particularmente por Calderón.Y es que, como ha notado muy bien Hector Santiestebán Oliva, Semíramis, como hija de una $\operatorname{ninfa}^{30}$ de Diana, es de una «noble [...] prosapia» ${ }^{31}$, lo que determina su actitud frente a la vida: aunque sea fruto de una violación infame ${ }^{32}$, su sangre es en parte divina, y el rechazo del temor $^{33}$, tanto como la valentía que la llevan a «arrostra[r] su destino ${ }^{34}{ }$ e en vez de sólo imaginarlo y temerlo,son muestras inconfundibles de su noble estirpe ${ }^{35}$. En este contexto, la

\footnotetext{
${ }^{30}$ Véase Diccionario de Autoridades, s. v. "nympha": «Fabulosa deidad de las aguas, bosques, selvas, etc.[...]». Véase en Grimal, 1994, p. 320: «Les Nymphes sont des "jeunes femmes" qui peuplent la campagne, les bois et les eaux. Elles sont les esprits des champs et de la nature en général, dont elles personnifient la fécondité et la grâce. Elles passent, dans l'épopée homérique, pour les filles de Zeus. Elles sont considérées comme des divinités secondaires, auxquelles on adresse des prières, et qui peuvent être redoutables. [...] Souvent, elles sont les suivantes d'une grande divinité (Artémis notamment), ou de l'une d'entre elles, d'un rang plus élevé. Ainsi les nymphes servantes de Calypso ou de Circé».

${ }^{31}$ Santiestebán Oliva, 2003, p. 309: «Es muy notable el parecido que comparten Segismundo en La vida es sueño, Semíramis en La hija del aire y Aquiles en El monstruo de los jardines. [...] Son originarios de una noble o nobilísima prosapia; desde reyes hasta dioses son los padres (Segismundo es hijo de los reyes de Polonia; Semíramis es hija de una ninfa; Aquiles es hijo de una diosa: Tetis)». Edwards, 1970, p. xxiv, bien señala que «The traditional Persian fertility goddess was Atargatis (whom Greeks called Derceto)», pero sin apuntar a un origen noble de la protagonista. Regalado, 1995, p. 905, comprueba que «En la versión calderoniana Semíramis es la hija de una ninfa de Diana y no de una semidiosa como lo es en el relato del historiador griego», pero no concluye de este linaje que tenga sangre divina. Rodríguez Rodríguez, 2002, por su parte, afirma, p. 312, que «es una mujer carente de sangre noble». Volveré más lejos sobre la lectura de este crítico.

${ }^{32}$ Véase Edwards, 1970, p. xxxvi: «In all sources which Calderón used we are told that Semiramis's mother, Derceto (or Derceta), seduced a young man, murdered him, abandoned the baby to which she gave birth, and then killed herself, all out of shame [...]. Calderón made substantial changes here. For seduction he sustituted rape, making Arceta an innocent victim of the young man's lust, she having been a chaste worshipper of Diana and he of Venus». Es llamativo que la crítica subraye el origen del mito reelaborado por Calderón sin sacar de ello ninguna conclusión. Esta eliminación de la violación, a mi modo de ver, contribuye al "ennoblecimiento" del personaje.

33 Véanse los posteriores empleos de las palabras «presunción» (vv. 172, 188), «valor» (v. 182), «vencido/ vencer» (vv. 185-186) en el final de esta secuencia, y en la secuencia final en romance -i-o de la primera Jornada: «Pero no me has de vencer, [Fortuna] / que yo, con valiente brío / sabre quebrarte los ojos» (vv. 721 723).

${ }^{34}$ Santiestebán Oliva, 2003, p. 313. Regalado, 1995, I, p. 882, interpreta este rasgo de manera muy diferente: «En La hija del aire Semíramis se vence a símisma, conquista esa dimension sensual y animal de su ser y toda debilidad que sea un impedimento a su voluntad de poder; pero, a diferencia de Segismundo, el vencerse a símisma la lleva a abrazar el mal»; p. 897: «Semíramis hace gala perversamente de ese ideal ascético que adoptan numerosos personajes calderonianos, el "vencerse a sí mismo", la maestría sobre uno mismo que conduce ya al autodominio como fundamento de la negación del mundo o a ese mandarse así mismo que mueve al tirano a dominarlo».

${ }^{35}$ Me parece muy llamativo que José Javier Rodríguez Rodríguez, en su excelente artículo sobre el papel de Lidoro en la obra, analice con máxima pertinencia la función de la nobleza de Lidoro en su trayectoria dramática bajo el seudónimo de Arsidas, y no repare en esta misma característica de Semíramis. Nota con acierto que «el comportamiento de Lidoro a lo largo de La hija del aire obedece, no tanto a un sentido cristiano-estoico de la moral, cuanto a una aguda conciencia del ser aristocrático y a un valor dispuesto al heroísmo para cumplir las
} 
palabra «ambición» se entiende mejor en su sentido de "deseo — todavía no "excesivo", en esta primera jornada de la primera parte - de homenaje u honor'. Unhonor anhelado por una protagonista que, a diferencia de Segismundo, sabe quién es y lo reivindicaa largo de la primera parte.

De ahí la firmeza con la que Semíramis encara heroicamente el oráculo de Venus: «¿Qué importa que mi ambición / digan que ha de despeñarme / del lugar más superior / si para vencerla a ella / tengo entendimiento yo?» (vv. 148-152): la ambición no es lo que caracterizará su ascenso, sino su futura caída. Por consiguiente, no se la puede considerar de entrada como el motor que impulsa la trayectoria la protagonista, sino más bien como el escollo que el hado pondrá en la realización de su trayectoria heroica. De ahí también el deseovital de poner a prueba su capacidad a vencerse a sí misma ${ }^{36}$, en el momento en que esta misma ambición, ya descontrolada («inordenatum appetitum honoris $\left.{ }^{37} »\right)$,pase a provocar su caída. Eso explicaque prefiera volverdeliberadamente a su gruta en vez de que la fuercen los soldados llamados por Tiresias («no quiere mi valor / darse a partido; y así, / para que no quedes hoy / vano de haberme vencido, / tengo de vencerme yo», vv. 182-186). Con esta actitud, hace una demostración inmediata de esta capacidad heroica a vencerse de la que piensa usar eventualmente en el momento en que su ambición cobre un carácter excesivo.

Este mismo rasgo heroicoes lo que transparece a las claras en su parlamento a Menón cuando, depués de relatarle en detalle el oráculo que la persigue, le declara:

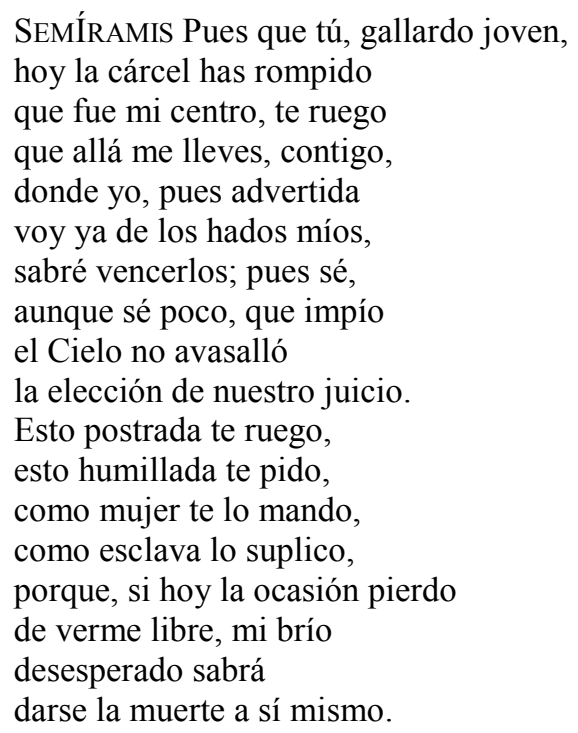

obligaciones que le son inherentes»; pero en lo que a Semíramis atañe, afirma que, en la segunda parte de la obra, «no hace aprecio de las normas de relación aristocráticas» (p. 310).

${ }^{36}$ Véase Santiestebán Oliva, 2003, p. 312: «Conociéndose a sí mismo y conociendo a dios, la fuerza radica en la valentía de actuar aun a pesar de los hados»».

${ }^{37}$ Véase Summa Theologica[44359] II ${ }^{\mathrm{a}}$-IIae, q. 131 a. 1. 
(I, vV. 965-982)

Aunque, en estos versos, el valor deSemíramis cobra la forma de un profundorespeto, no es nada incompatible con su caracterización heroica ${ }^{38}$, ni menos aún se trata aquí de un ardid mujeril que dé rienda suelta a su ambición convenciendo a Menón de que la saque de su gruta $^{39}$.Al contrario, dicha humillación voluntaria es muestra de la noble sumisión, de índole vasálica, por la que la protagonista acepta volverse la obligada del gobernador que, merced a su generosidad, le va a dar la vida al permitirle enfrentarse con su futuro entre los hombres: «SEMÍRAMIS- que voy a ser racional / ya que hasta aquí bruto he sido» (vv. 1005-1006).

Volveremos a encontrarel motivo de la obligación que se manifiesta con más vigencia aúnmediante la dialéctica del don y del agradecimiento vasálico ${ }^{40}$ cuando,al principio de la jornada segunda, Semíramis, ahora liberada de su cueva, recibe de Menón la noticia de que tiene que quedarseimperativamente entre los aldeanos de Ascalón: «Bien, Menón, / muestras así cuánto son / los acasos de mi suerte / $\operatorname{vasallos}^{41}$ de tu albedrío» (vv. 1043-1045). Es que la inicial generosidadde Menón, al recluirla en la quinta,se está transformando en tiranía, como él mismo lo confiesa: «Tú a mi amparo agradecida / y con el amor enojada, / mi amparo te halló obligada / y mi amor te halló ofendida / [...] Pues si ocultarte pudiera, / tanto mi amor te ocultara, / que ni el Sol viera tu cara / ni el aire de ti supiera. / Si hacerla pudiera, hiciera / una torre de diamante...» (vv. 1085-1090). La repetida sumisión de Semíramis ${ }^{42}$, lejos de ser una traza motivada porla promesa matrimonial hecha por el gobernador ${ }^{43}$, manifiesta otra vez dos rasgos de su caracterización dramática: por una parte, es respeto de la palabra dada ynoble

\footnotetext{
${ }^{38}$ Véase Hernández Araico, 1985, p. 33: «Estas palabras manifiestan el carácter varonil de esta amazona que no piensa en someterse al hombre. Pero poco más adelante, Semíramis se contradice declarándose sumisa para lograr su libertad».

${ }^{39}$ Véase Hernández Araico, 1985, p. 33: «Antes de analizar el aspecto femenil de su personalidad, conviene ver la traza montaraz que pretende trascender con tácticas típicas de mujer débil, atenida y fingida»; p. 35: «Finge una docilidad típicamente femenina con fin de llagar a salir de su encierro en los montes como esposa de Menón. Desde un principio Semíramis ha visto en él su única posibilidad de lograr libertad y por eso ha aparentado ser sumisa cuando la saca de su prisión. [...] Bajo la apariencia de mujer débil y sumisa que Semíramis intenta proyectar, hierve el dinamismo de su personalidad varonil impetuosa». Véase también Lipmann, 1982, p. 45: «But after Menón releases her, she seems genuinely feminine».

${ }^{40}$ Véase Vitse, 1999, las meridianas páginas 30 a 33. Creo que Lipmann, 1982, p. 46, interpreta mal la sumisión de Semíramis: «This speech gives the first indication in the play that Semíramis's perception of others are distorted, and that she does not grasp fully how she is perceived. Before Menon's departure, she had been absolutely submissive, consigning her albedrio and even her identity to Menón's care».

${ }^{41}$ Véase también, en este mismo sentido, la alusión a la «lealtad» de Semíramis, v. 1100.

${ }^{42}$ Edwards, 1970, p. xlii, subraya que «If Semíramis expresses ambitious aims early on, she is nevertheless torn between such aims and loyalty to Menón, to whom she is extremely grateful»; pero p. lxi: «If Menón seeks her love, she seeks only more freedom of choice, and this does not of necessity include love for Menón. She is grateful to him but her aims are far more ambitious [...]. Furthermore, the ambition of Semíramis cannot possibly at this stage be considered a bad thing».

${ }^{43}$ Véase Hernández Araico, 1985, p. 35: «La promesa matrimonial de Menón entonces aplaca a Semíramis a tal grado que finge una sumisión absoluta negándose a sí misma totalmente».
} 
aceptación de la jurisdicciónreal sobre el derecho a casarse de sus súbditos. Por otra parte,es nuevo ejemplo del valor que le permite vencerse a sí misma: «Tan sagrado es el preceto / tuyo, que, humilde y postrada, / vivir del Sol ignorada, y aun de mí misma, prometo» (vv. 1105-1108). Lo cual no impide que Semíramis mantenga intacto su anhelo de homenaje inicial, que se expresa con mucha sencillez en su aprecio de la compañía de los villanos de Ascalón: «porque ellos fueron / en quien lisonja hallé alguna, / cuantas veces importuna / atormenta mis cuidados / la tormenta de mis hados y el rigor de mi fortuna» (vv. 1119-1124).

Sin embargo, después de salido Menón hacia la corte, Semíramis pone en tela de juicio su obligación de quedarse en la aldea; pero en vez de serexpresión de su ambición frustrada ${ }^{44}$, su monólogoreúne precisamente los principaleselementos dramáticos de la heroicidad aristocrática:

\author{
SEMÍRAMIS Ya, \\ grande pensamiento mío, \\ que estamos solos los dos, \\ hablemos claro yo y vos, \\ pues sólo de vos confío. \\ Mi albedrío, ¿es albedrío \\ libre o esclavo ${ }^{45}$ ? ¿Qué acción, \\ o qué dominio, elección \\ tiene sobre mi fortuna, \\ que sólo me saca de una \\ para darme otra prisión? \\ Confieso que agradecida \\ a Menón mi voluntad \\ está; pero ¿qué piedad \\ debe a su valor mi vida \\ de un monte a otro reducida? \\ Aunque, si bien lo sospecho, \\ la causa es que de mi pecho \\ tan grande es el corazón, \\ que teme, no sin razón, \\ que el mundo le viene estrecho, \\ y huye de mí. En fin, ¿jamás \\ más que un bruto no he de ser? \\ ¡Cielos! ¿No tengo de ver, \\ sino imaginar no más, \\ cómo es el vivir? \\ (I, vv. 1134-1159)
}

\footnotetext{
${ }^{44}$ Véase Hernández Araico, 1985, p. 35: «Al principio del segundo acto, Semíramis resiente que Menón no la lleve a la corte por recluirla aún en el campo. [...] tan pronto sale Menón, se desahoga de su frustración de estar "de un monte a otro reducida"».

${ }^{45}$ Véase Lipmann, 1982, p. 56: «The references to the notion of free will in La hija del aire thus do not provide a framework for judging the characters'actions that similar allusions create in La vida es sueño. On the contrary, these allusions in La hija del aire underscore the confusion or the pagan characters and suggest the inevitability of a tragic outcome». Siguiendo esta opinión de Lipmann, no pienso que estos versos tengan nada que ver con el concepto cristiano de libre albedrío, sino que aquí refieren directamente a los ya citados versos «Bien, Menón, / muestras así cuánto son / los acasos de mi suerte / vasallos de tu albedrío» (vv. 1043-1045), en los que comprueba la protagonista la deuda que le tiene a su liberador.
} 
Típicos del personaje noble son aquí la amplitud o generosidad ${ }^{46}$ en sentido etimológico $^{47}$ — de sus sentimientos («grande pensamiento mío», v. 1135; «de mi pecho / tan grande es el corazón», vv. 1151-1152; «el mundo le viene estrecho [a mi corazón $\left.{ }^{48}\right] », \mathrm{v}$. 1154), el enfrentarse con su destino (v. 1136-1137), el valor como dinamismo («qué acción, / o qué dominio, elección», vv. 1140-1141), y el agradecimiento ante la benevolenciade los que Semíramis hace muestra: «Confieso que agradecida / a Menón mi voluntad / está» vv. 11451147. Pero también es consecuencia de esta misma gratitud decepcionadala rebelión ante un sentimiento que, al tomar un cariz tiránico, ya se revelainnoble en Menón: «pero ¿qué piedad / debe a su valor mi vida [...]?» (vv. 1147-1149). Finalmente, es la aceptación del riesgo vital $^{49}$ la que se hace patente en el anhelo del «vivir» opuesto al «imaginar no más» (v. 1158).

La relación que hace de Semíramis la obligada de Menón se prolonga incluso durante la ausencia de éste, y condiciona el desarrollo del encuentro de Semíramis con el rey Nino, al que ella todavía no puede identificar como tal. Al oír los gritos que acompañan la carrera loca del caballo real, ella exclama: «¿Cómo pudiera el valor / que está brotando en mi pecho / dar vida al gallardo joven / que se despeña? » (vv. 1705-1708). Arrancándole su bastón al gracioso Chato,Semíramis interrumpe el galope del caballo y provoca la caída de su jinete.Tal conducta,impulsiva y sorprendentemente varonil — Sirene, la mujer de Chato, calificará a

\footnotetext{
${ }^{46}$ No me adhiero a la interpretación de estos versos por Cruickshank, 2002, p. 358, que considera que «Semíramis is too inexperienced to recognise that this feeling is ambition».

${ }^{47}$ Véase Autoridades, s. v. 'generosidad': «En su riguroso sentido significa nobleza heredada de los mayores. Viene del latín generositas».

${ }^{48}$ Sigo la nota al verso 1254 (en realidad 1154) de Edwards, 1970, p. 279: «There are many examples en the Golden Age of the use of temer followed by the indicative.-See Keniston, para. 28.265. Keniston = H. Keniston, The Syntax of Castilian Prose. The Sixteenth Century, Chicago, 1937». Doy entonces a estos versos un sentido muy distinto del que le confiere Lipmann, 1982, p. 46, donde hace de Menón el sujeto de los verbos 'temer' y 'huir' «que teme, no sin razón, / que el mundo le viene estrecho, / y huye de mí» (vv. 1153-1155): «But now, reasoning out the cause of her renewed inprisonment, she mistakenly guesses that he fears her corazón and forgets that in her secretiveness she has given him no inkling that she is ambitious». Entiendo (y le agradezco aquí su ayuda a Federico Serralta) los vv. 1147 a 1159 de la manera siguiente: "¿Qué le tengo de agradecer a Menón, cuando me quiere volver a encerrar en otra manera de cárcel? Sospecho que si me hago tal pregunta, es porque mi corazón es tan grande que teme que el mundo le quede estrecho, y teme que el mundo huya de mí. Y si me huye el mundo, ¿saldré algún día del estado de bruto, sin experimentar lo que es el vivir?"

${ }^{49}$ Creo errónea la lectura propuesta por Regalado, 1995, I, pp. 868-869: «Tras las apariencias del ambiente idílico y sereno del retiro campestre y la aparente sumisión de la que Semíramis da muestras, se impone la voluntad de poder de la protagonista, esa fuerza que la mueve y que todavía no domina yque se explica a sí misma como la grandeza de un corazón al que "el mundo le viene estrecho". Ese "grande pensamiento" y "grande corazon" alienta el impetú que la mueve y que salta los objetos representables, un más allá que no satisface la ambición de la imaginación. Ávida de experiencia, Semíramis se angustia ante ese solo imaginar el vivir; de ahí su temeraria voluntad a la que da voz en la escena inicial de la primera jornada "que quiero morir del rayo, / y de solo el trueno no". El querer "morir del rayo" y no del "trueno", morir de la "verdad" y no de la "imaginación", presupone una resolución desesperada que abraza el conocimiento en la prueba experimental de la propia carne y del propio espíritu, lejos de toda cautela epistemológica. [...] En la figura demoníaca de Semíramis, Calderón representó la esencia de la voluntad de poder, creación que encontró poderosos ecos en el espíritu romántico siglo y medio después».
} 
Semíramis de «marimacha ${ }^{50} »$ ocasiona el comentario entre incrédulo e irónicamentesagazdel gracioso: «Luego / que de pellejos cargada / la vi en el lance primero, / dije: "aquesta tiene cara / de echar caballos al suelo"» (vv. 1720-1724). Más allá de su divertida e improbablesagacidad, la fanfarronería de Chato subrayala coherencia de la trayectoria dramática de Semíramis: lo que se esbozaba en la primera jornada como íntima convicción de su valor, en la segunda jornada se hace acción a través de la hazaña.

El consiguiente encuentroentre los dos protagonistas de alta estirpe da lugar a un reconocimiento inmediato de sus respectivas cualidades ${ }^{51}$. Nino sospecha queSemíramis, por lo menos a causa de su belleza, es «deidad de estos montes» (v. 1735), y la describirá luego a sus cortesanos subrayando que «villano es el traje, pero / tan noblemente villano» (vv. 17941795), mientras ella reconoce en el rey a un «i[...] generoso mancebo!, / cuyo semblante, no sé / por qué secreto misterio, / a amor y a veneración / me está provocando a un tiempo» (vv. 1744-1749). Aunque el léxico empleado por Semíramisse parezca al de un encuentro amatorio, no se trata aquí de un banal flechazo que llevaría a la mujer salvaje a pasar por altoel más elemental recato mujeril ${ }^{52}$. Lo que está en obra en Semíramis es la intuición de la estirpe real de Nino, y de los honores que se deben a su rango. En esta situación dramática, como al principio de la primera jornada, la palabra «amor» es ante todo sinónima de la «veneración»o reverencia que el súbdito profesa por su señor natural ${ }^{53}$. De ahí que no se puedan interpretar las palabras de Semíramis como una confesión descarada del agrado sensual que le procura su encuentro con $\mathrm{Nino}^{54}$, aunque éste experimente inmediatamente, al verla, una pasión incontrolable.

\footnotetext{
${ }^{50}$ Véase I, II, v. 1720: «¿Hay tal marimacha?».

${ }^{51}$ Véase cómo Nino describe a Semíramis ante Irene, I, II, v. 1789-1796: «que al que una deidad humana / en él hallare primero / y la traiga a mi presencia, / grandes mercedes le ofrezco. / Por que no dudéis las señas, / villano es el traje, pero / tan noblemente villano, / que su Rey le rinde el pecho». Luego la compara con Venus (v. 1802), Diana (v. 1803), o sus ninfas Amaltea (v. 1804), Aretusa (v. 1805).

${ }^{52}$ Véase Hernández Araico, 1985, p. 31: «Calderón la presenta [...] como una mujer rústica, hombruna y muy desenvuelta en sus ocasionales encuentros con los hombres»; p. 34: «Por su gran belleza, Semíramis será una noble salvaje; pero no deja de ser montaraz. Su fuerza física lo constata en el segundo acto cuando se arroja a salvar al rey tropezando su caballo desbocado. Esta hazaña le otorga el calificativo de "marimacha" (I, ii, 1819). Al mismo tiempo, su proeza simboliza su aspecto sensual porque ella causa la caída del caballo que, desde la antigüedad, representa el predominio de la pasión sobre la razón. Semíramis recoge, pues, la tradición de serranas forzudas y sensuales. Ya desde que sale de su prisión y asombra a Menón con su belleza, se ha mostrado bastante desenvuelta (I, I, 785-790). Su sensualidad se patentiza al hablar con el rey por primera vez después de haber tumbado su caballo. [...] Rústica e ingenua, Semíramis no se exime de declarar el placer que le ocasiona este joven».

${ }^{53}$ Véasesupra, nota 15.

${ }^{54}$ Véase Lipmann, 1982, p. 46: «In the scenes after she saved Nino's live, Semíramis's naïveté and impulsiveness are apparent again. At first she appears feminine, fleeing Nino in an attempt to keep her promises to Menón, though she confesses to Nino that his 'semblante, no sé / por qué secreto misterio, / a amor y a veneración / me está provocando a un tiempo'».
} 
En cuanto a la reticencia de Semíramis a revelar su identidad al soberano ${ }^{55}$, tampoco se puede atribuir a un solapado cálculo ${ }^{56}$ : sigue siendo la muestra de la relación de obligación que la liga a Menón, como lo dejan entender sus temores de parecer ingrata: «Ocultarme por aquí / de tanta gente quisiera, / para que nunca pudiera / quejarse Menón de mí» (vv. 18761879). Una fidelidad que, por otra parte, transparece de modo inequívoco en las palabras que dirige a Menón cuando finalmente se descubrenrecíprocamente en el monte: «Mi bien, mi señor, mi dueño» (v. 1924). Cuando se niega a huir como Menón se lo aconseja para evitar el encuentro con el rey («Huye, Semíramis bella ${ }^{57} »$, v. 1933), no es porque ella se ha percatado de la identidad de $\mathrm{Nino}^{58}$ — que todavía no ha salido al escenario-, sino porque su valor le impide cualquier huida: «QQué es huir mi altiva estrella?», v. 1934. De ahí el comentario de Nino-que restablezco aquí bajo la forma que tiene en la edición de Vera Tassis ${ }^{59}$ — «y tú, crüel, que entre fieras / rudas das de huir indicio, / cuando haces un beneficio, / como si un agravio hicieras»(vv. 1960-1963), y la respuesta de Semíramis al ser tratada de «medrosa» (v. 1968): «Esto en mí no es temor, / que fuera decirlo error» (vv. 1973-1974).

Estoy pues en total desacuerdo con las lecturas que hacen de Semíramis, en esta fase de la segunda jornada, una ambiciosa fría y calculadora ${ }^{60}$ cuando, al pedir su mano

\footnotetext{
${ }^{55}$ Véanse los versos 1737-1741, 1749-1750, 1751, 1754-1755, 1756-1757, 1761, y, sobre todo, el aparte de los vv. 1762-1765: «Huiré al monte; que no quiero / que piense Menón jamás / de mí que no le obedezco».

${ }^{56}$ Véase Hernández Araico, 1985, p. 31: «No obstante su desenvoltura, Semíramis no le revela su identidad [a Nino] porque Menón, al prometerle matrimonio, le ha pedido que permanezca en el "florido monte" (I, ii, 1031). Y como pretende trascender su rusticidad por medio de Menón, Semíramis posterga su pasión por el jinete y trata de esconderse otra vez para complacer al general».

${ }_{57}$ Véase Ruiz Ramón, 1987, p. 140, v. 1933: «Huye. Semíramis bella», lo cual no se entiende, debido a un error de imprenta. Por otra parte, comparto la lectura de Ruiz Ramón que hace del verso siguiente una réplica de Semíramis, al contrario de Edwards, 1970.

${ }^{58}$ Edwards, 1970, p. xliii: «Thus, when Semíramis flees from Nino during the hunting scene, she does so not only because she whishes to remain loyal to Menón but also because she is not aware of Nino's identity. As soon as she knows who he is, during the fight between Menón and Arsidas, she ignores Menon's advice that she should run away».

${ }^{59}$ Edwards utiliza dos ediciones (pp. 1xii-lxxxiii) para su establecimiento del texto: la edición de Vera Tassis, y la Tercera Parte de comedias de D. Pedro Calderón de la Barca, fechada de 1664. Esta última es la que sigue Ruiz Ramón para los vv. 1960-1963: «y tú, cruel, que, entre fieras / dudas, das de amor indicio / cuando haces un beneficio, / como si agravio hicieras». Esta lectura no me parece coherente con los versos siguientes, ni con la calificación de Semíramis de «medrosa» en el v. 1968, ni con la reacción ultrajada de la misma. Tampoco entiendo a qué «dudas» se referiría Nino en este caso.

${ }^{60}$ Véanse Edwards, 1970, p. 1xiii: «Ambition becomes a bad thing only when, in an attempt to obtain power, she begins to take cold-blooded advantage of the feelings of Nino and Menón for her, fanning their rivalry and exploiting their passion as a springboard for her own ambitions»; p. lxiv: «It is also the labyrinthine landscape of the hunt that the ambition so Semíramis begins to take on a more cold-blooded tone. Becoming aware now of Nino's identity and of his real interest in her, she rejects any obligation to Menón»; Lipmann, 1982, pp. 46-47: «Nino is also dazzled by her beauty and demands to know precisely what Menon's relationship is to Semíramis after they have hunted her down. Anticipating that Menón, who refers to her as 'mi dama', will misrepresent his claim on her affections, she interrupts with a startling display of aggressiveness and hauteur, referring to herself in metonymies like those she used in the first act. She takes special care to point out that she is not formally betrothed to Menón and that she has not slept wiht him, despite appearances to the contrary»; Weimer, 2008, p. 401: «Esta pasión idólatra y desenfrenada [de Menón] no disminuye a lo largo de la obra, incluso después de que
} 
elperentorio Menón(«Dadme esa mano», v. 2023) y al diferir su permiso Nino para saber «el estado / en que con ella» (v. 2026-2027) se halla su general, ella toma la palabra para contestar:

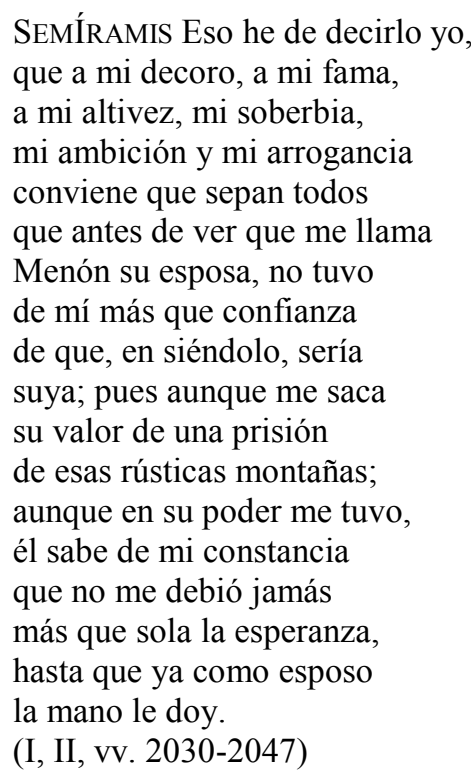

El referirse la propia Semíramis a su «decoro», su «fama», su «altivez», su «soberbia», su «ambición» y su «arrogancia» cuando reivindica su castidad evidentemente no funciona como una improbable y brutal confesión de su immoderada ambición, sino como nuevo y valiente intento de independizarse de la tiránica obligación en la que la tiene Menón,paraadueñarse de su destino confiscado provisionalmentepor las dos figuras masculinas. Con estas palabras, Semíramis reafirma la castidad intrínseca a su calidad de descendiente de ninfa de Diana, a la vez queacude a la dialéctica del don, iniciada por Nino en los versos precedentes: «cuando haces un beneficio» (v. 1962). Utiliza la obligación con la que Menón quiere aprisionarla para descartar toda sospecha relativa a su decoro («aunque me saca / su valor de una prisión [...]; / aunque en su poder me tuvo / [...] no me debió jamás / más que la sola esperanza» (vv. 20392042 y v. 2045),invirtiendo esta obligación al postergarel don de sí mismaen la perspectiva de un matrimonio en el que Menón ya toma el estatus de acreedor del beneficio que le hará Semíramis («no me debió jamás / más que la sola esperanza, / hasta que ya como esposo / la mano le doy» (vv. 2045-2047).

Las cosas se hacen aún más complejas cuando esta dialéctica del intercambiose desplaza a otros protagonistas: sedifuminala relación tiránica entre Menón y Semíramis en 
beneficio de la que une ahoraal propio soberano consu salvadora («no es buen día en que se casa / dama a quien debo la vida», vv. 2049-2050; «a ti, divino / pasmo de aquestas montañas / la vida debo» vv. 2056-2058), y el juego del dar y del agradecer ${ }^{61}$ se ensancha cuando Nino somete a su rival recordando la privanza que lo une a su general («A ti, Menón, debo cuantas / victorias hoy me coronan», vv. 2053-2054) para, so capa de generosidad, forzarlo a diferir el momento de la boda: «Y, así, con demostraciones varias / honrar pretendo a los dos», v. 20592060. La ambiciónde Semíramis -como justo apetito del honor debido a su rango-se manifiesta, en esta ocasión, en su inmediata aceptación del homenaje («Si el Rey quiere honrarnos, / Menón, con mercedes tantas, / no a mi presunción le quites / la vanidad de lograrlas», v. 2072-2075), que podemos leer como una nueva afirmación de su valor, dispuesto paraafrontar el riesgo inscrito en el oráculo en vez de quedarse en el mundo protegido de la imaginación. Lo confirman sus últimas palabras, pronunciadas en aparte antes de salir del escenario:

\author{
SEMÍrAmis[Aparte] Altiva arrogancia, \\ ambicioso pensamiento \\ de mi espíritu, descansa \\ de la imaginación, pues \\ realmente a ver alcanzas \\ lo que imaginastes; pero \\ aun todo aquesto no basta, \\ que para llenar mi idea \\ mayores triunfos me faltan. \\ (I, II, vv. 2096-2105)
}

De modo que, en este acto segundo, en ninguna manera se tratóde fría ambición calculadora ni de manipulación abusiva de los sentimientos amorosos despertados por la bella protagonista $^{62}$, sino, más allá de la aceptación generosa de las leyes del intercambio vasálico,

\footnotetext{
${ }^{61}$ Véase Vitse, 1999, p. 32, a propósito de los personajes de Rosaura y Clotaldo: «A partir de là se multiplieront, tout au long de l'œuvre, les manifestations de cette pitié qui n'est autre qu'un aspect de la valeur [...]. S'établit entre le protecteur et son protégé un échange — don, guerdon- où chacun fait assaut, respectivement, de libéralité et de confiance reconnaissante».

${ }^{62}$ Véase Edwards, 1970, p. xliii: «Aware of Nino's interest in her, she makes the point that she is under no real obligation to Menón, and a sense of cunning previously unsuspected in her character begins to reveal itself [...]. She shares Nino's opinion that her wedding to Menón would be better postponed, and, as in the King's case, there is a striking disparity between her avowed reasons and her real intentions»; p. lxix: «Her agreement with Nino that her wedding should be delayed, while appearing to be based on a desire to have a more splendid affaire, really has an ulterior motive as devious as his. And if Semíramis is perfectly free to deny any relationship with Menón, she would clearly be justified in rejecting him for Nino only if she did it for love. From the timing of her decisions, however, and from the manner in which she matches her plans those of the King, it is obvious that she regards the situation as a stepping-stone to greater things. She is begining to manipulate people. Ambition becomes a perversion».
} 
del fundamental valor que la incita a encarar el destino previsto por el oráculo, en vez de huirlo o de sólo imaginarlo ${ }^{63}$.

El tercer acto de la primera parte lleva a su plena realización la aspiración heroica del personaje femenino acogido triunfalmente en Nínive ${ }^{64}$, y completa el oráculo de Venus que anuncia «que a un Rey / glorioso la haría [s]u amor / tirano» (vv. 139-141). Pero es también el momento en que el apetito de honores de Semíramis se hace excesivo, coloreando negativamenteuna ambición que hasta ahora procedía prioritariamente de la noble energía vital de la protagonista. En este tercer acto, las dos facetas de esta ambición_virtus ${ }^{65}$ heroica por una parte, exceso de esta virtuspor otra-, convivenen una tensión conflictivaqueevidencia la complejidad de la heroína. De ahí que Semíramis pueda a un tiempo, a lo largo de este tercer acto de la primera parte,denigrar el esplendor de Nínive $^{66}$ y humillarse ante su príncipe ${ }^{67}$, mantener su lealtad hacia Menón, ${ }^{68}$ y no necesitarlo más ${ }^{69}$;abandonarlo cuando el rey le retira su favor al privado ${ }^{70} \sin$ tolerar que lo ejecute ${ }^{71}$, defender su castidad de los asaltos de $\mathrm{Nino}^{72}$ y aceptar casarse con él para ser reina ${ }^{73}$, ejemplos todosde ambición que efectivamente abundan en esta tercera jornada.

\footnotetext{
${ }^{63}$ No comparto pues la lectura de Regalado, 1995, I pp. 865-866: «Semíramis llama a esa magnitud de la imaginación "ambicioso pensamiento de mi espíritu", al que pide que cese ante la presencia del objeto imaginado [...]. Mas el objeto representable no satisface la ambición de la imaginación ante la que lo actual y real no "basta". Semíramis, azuzada por el deseo que la mueve, necesita "mayores triunfos" para "llenar" su "idea", es decir, no se contenta con la certidumbre, la adaequatio rei et intellectus. Lo que imagina, la idea que quiere llenar, es la ambición misma, la voluntad de poder que no logra satisfacer en las apariencias».

${ }^{64}$ Véase I, III, v. 2238: «iViva Semíramis bella!»; vv. 2266-2267: «iViva la que dio la vida / a Nino, Rey generoso!».

${ }^{65}$ Véase Gaffiot, 2000, s. v. virtus: «virtus, utis, f. (vir): qualité qui font la valeur de l'homme moralement et physiquement; 1. caractère distinctif de l'homme, [et en gén.] qualité distinctive, mérite, essentiel, valeur caractéristique, vertu». Véase también Autoridades, s. v. 'virtud': «Significa también fuerza, vigor o valor».

${ }^{66}$ Véase I, III, vv. 2293-2303: «SEMÍRAMIS- Me ha parecido poco [el eplendor de Nínive]. / Mas no me espanto, porque / objeto es más anchuroso / el de la imaginación / que el objeto de los ojos. / Imaginaba yo que eran / los muro más suntuosos, / los edificios más grandes, / los palacios más eminentes / y todo, en fin, más famoso».

${ }^{67}$ Véase I, III, vv. 2274-2275:«Más dichosa quien de vos / tuvo aplausos tan heroicos».

68Véase I, III, vv. 2411-2421: «Conozco / que debo a Menón, señora, / todas las dichas que gozo; / y como de agradecida / hay un término tan corto / a enamorada, decir / que lo estoy será forzoso; / si bien es a mi presencia / tal que...» «IRENE- Dilo» «SEMÍRAMIS-Que me corro / de que haya de ser mi dueño / quien es vasallo de otro».

${ }^{69}$ Véase I, III, vv. 2322-2326: «Mas, ¿para qué le echo de menos, / si tantos aplausos logro / sin él? Como estos no falten, / lo demás importa poco».

${ }^{70}$ Véase I, III, vv. 2782-2791: «Del Rey en desgracia estás, / sin privanza y sin estado, / fugitivo y desterrado, / de su vista huyendo vas. / No puedo hacer por ti más / hoy que el no ser tu esposa, / que hermosa mujer no hay cosa / que tanto a un pobre le sobre, / porque es sátira del pobre / el tener mujer hermosa».

${ }^{71}$ Véase I, III, vv. 3006-3016: «Yo lo estimo, por pagarle, / señor, y porque me deje, / viéndose ya en paz conmigo; / que si una vida le debe / mi ser, dándole otra vida / ya ningún derecho tiene / contra mí. Y así, Menón, / pues en paz estamos, vete, / y déjame que yo logre / de mi destino la suerte».

${ }^{72}$ Véase I, III, vv. 3059-3067: «Detente, / señor, que si agradecida / a tus honras y mercedes / me mostré, [...] / cuando pienses / que son favores de amor, / más que me ilustran, me ofenden».

${ }^{73}$ Véase I, III, vv. 3136-3137: «El ser tu esclava será / mis rayos y mis laureles».
} 
Ya es hora de concluir: mi propósito en este trabajo eramostrar que se puede matizar la apreciación de la ambición de Semíramis, considerada por la crítica como un afán de poder desmesurado constante desde el principio de la trayectoria dramática de la protagonista. Creo que, en vez de leerla de modo monolíticamente negativo, se la debe considerar como elemento fundamental de la caracterización heroica de Semíramis. A partir del momento en que se encuentra la protagonista en la corte, finalmente destinataria de este homenaje que tanto la conmovía en la escena apertural de la primera jornada, el appetitum honorisque la anima se hace progresivamente inordinatum, 'excesivo', en la medida en que, por primera vez desde el principio de la comedia, los valores aristocráticos que hasta ahora le dieron su coherencia dramática se ven supeditados al afán de poder. De hecho, al final del tercer acto, por primera vez se rebaja Semíramis a ser la obligada de un personaje cuyo valor se revela inferior al suyo, y olvidándose de lo que se debe a sí misma, favorece el placer que los homenajes de un estatuto real le proporcionan en detrimento de la conservación de su aspiración heroica.

De ahí que pueda confesar en aparte «Yo haré, si llego a reinar, / que el mundo mi nombre tiemble» (vv. 3142-3143), porque el reinar, si se fundamenta en excesivo apetito de homenaje, ya no funciona como consagración merecida de la nobleza a través del natural ejercicio del poder, sino como tiranía, en la que la espontanea veneración se torna en temor. Queda ahora por interrogarse sobre la coherencia internaque impide que Semíramis consiga vencerse a sí misma, mientras que al principio de la obra declaraba:

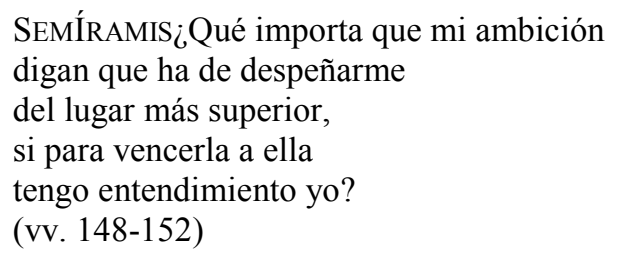

Pero eso será el objeto de otro trabajo.

\section{Bibliografía}

BRAVO, Frédéric, «La hija del aire, méta-drame d'un personnage vide», Littéralité I, 1989, pp. 23-49.

CHIAPPINI, G., «Estética, retórica y técnicas de la pintura verbal: el 'retrato' de La hija del aire de Calderón», in Philologica, homenaje al Profesor Ricardo Senabre, Cáceres, Universidad de Extremadura, 1996, pp. 129-147.

CRUICKSHANK, Don W., «The Second Part of La hija del aire» in Bulletin of Hispanic Studies, 62 (1984), pp. 286-294.

— «The significance of Fortuna in Calderón's La hija del aire», «Never Ending Adventure» :studies in medieval and early modern spanish literature in honor of Peter N. Dunn, edited by Edward H. Friedman and Harlan Sturm, Newark, Juan de la Cuesta, 2002, pp. 351-376. 
EDWARDS, Gwyne, La hija del aire, London, Támesis, 1970.

FISHER, S., «The Psycological Stages of Feminine Development in La hija del aire: a Jungian Point of View», Bulletin of the Comediantes 34 (1982), pp. 137-158.

FROLDI, Rinaldo, «La gran comedia de La hija del aire», Teatro calderoniano sobre el tablado. Calderón y su puesta en escena a través de los siglos. XIII Coloquio Anglogermano sobre Calderón, Florencia, 10-14 de julio de 2002. Actas editadas por Manfred Tietz, Archivum Calderonianum. Stuttgart, Steiner, 2003, pp. 145-161.

GAFFIOT, Félix, Dictionnaire Latin-Français, Paris, Hachette, 2000.

GRIMAL, Pierre, Dictionnaire de la mythologie grecque et romaine, Paris, PUF, 1994.

HERNÁNDEZ ARAICO, Susana, «Texto y espectáculo en La hija del aire. Escenificación triangular de un metadrama trágico»,Segismundo 17 (1983), pp. 27-35.

— «La Semíramis calderoniana como compendio de estereotipos femeninos», Iberomania 22 (1985), pp. 29-39.

HESSE, Everett W., «Los dos retratos de Semíramis», Estudios sobre el Siglo de oro en Homenaje a Raymond R. McCurdy, Madrid, Cátedra, 1983, pp. 151-157.

LIPMANN, S. H., «The Duality and Delusion of Calderón's Semíramis», in Bulletin of Hispanic Studies, 59 (1982), pp. 42-57.

McKENDRICK, M., Woman and Society in the Spanish Drama of the Golden Age, Cambridge, Cambridge University Press, 1974.

REGALADO, Antonio, Calderón. Los orígenes de la modernidad en la España del Siglo de Oro, Barcelona, Destino, 1995.

RODRÍGUEZ RODRÍGUEZ José Javier, «El papel de Lidoro en La hija del aire», Calderón 2000, Homenaje a Kurt Reichenberger en su 80 cumpleaños, ed. Ignacio Arellano, Kassel, Edition Reichenberger, 2002, vol. II, pp. 305-313.

ROGERS, DANIEL de W., «¡Cielos! ¿Quién en Ninias habla? Mother-son impersonation inLa hija del aire», Bulletin of the Comediantes 20 (1968), pp. 1-4.

— «La imaginación de Semíramis», in Hacia Calderón, II Coloquio angloamericano, Berlin, W. de Gruyter, 1973, pp. 171-179.

RUIZ RAMÓN, F., La hija del aire, Madrid, Cátedra, 1987.

SANTIESTEBAN OLIVA, Héctor, «Paralelismos monstruosos calderonianos. Segismundo, Semíramis, Aquiles; monstruos de La vida es sueño, La hija del aire, El monstruo de los jardines», Estudios del teatro áureo, Texto, espacio y representación, México, Universidad Autónoma Metropolitana, el Colegio de México; [S.1.], Asociación Internacional de Teatro Español y Novohispano de los Siglos de Oro, 2003, pp. 307-315.

VITSE, Marc, «La descripción de Lisboa en El burlador de Sevilla», Criticón 2, 1978, pp. 21-41.

— «El teatro en el siglo XVII», Historia del teatro en España, dirig. K. Ma. Díez Borque, I, Madrid, Taurus, 1983, pp. 473-706.

-Éléments pour une théorie du théatre espagnol du XVII ème siècle, Toulouse, France-IbérieRecherche, Université de Toulouse-Le Mirail, 1988.

- Segismundo et Serafina, Toulouse, PUM(Anejos de Criticón, 12), 1999 (1ª . ed., 1980).

WEIMER, Christoph, «Tiresias y lo trágico en La hija del aire», Hacia la Tragedia aúrea: lecturas para un nuevo milenio, De Armas, L. García Lorenzo, E. Garía Santo-Tomás eds., Biblioteca Aúrea Hispánica 55, Madrid-Iberoamericana, Frankfurt-Vervuert, 2008, pp. 397-405. 